Am Rande der Fotografie 

Katharina Steidl

\section{Am Rande der Fotografie}

Eine Medialitätsgeschichte des Fotogramms

im 19. Jahrhundert 


\section{(cc) BY}

Open Access: Wo nicht anders festgehalten, ist diese Publikation lizenziert unter der Creative-Common-Lizenz Namensnennung 4.0; siehe http://creativecommons.org/licenses/by/4.0.

\section{Library of Congress Control Number: 2018956059}

\section{Bibliografische Information der Deutschen Nationalbibliothek}

Die Deutsche Nationalbibliothek verzeichnet diese Publikation in der Deutschen Nationalbibliografie; detaillierte bibliografische Daten sind im Internet über http://dnb.dnb.de abrufbar.

(c) 2019 Katharina Steidl, publiziert von Walter de Gruyter GmbH, Berlin/Boston.

Dieses Buch ist als Open-Access-Publikation verfügbar über www.degruyter.com, https://www.doabooks.org and https://www.oapen.org.

Lektorat: Martin Steinbrück Layout und Satz: Petra Florath Cover: SCHR/GSTRICH, Kommunikationsdesign Coverabbildung: Anna Atkins, Alaria esculenta, Cyanotypie, 1844/45, aus dem Album: „Photographs of British Algae. Cyanotype Impressions“, Part XII, New York Public Library Druck und Bindung: Beltz Grafische Betriebe GmbH, Bad Langensalza www.degruyter.com 